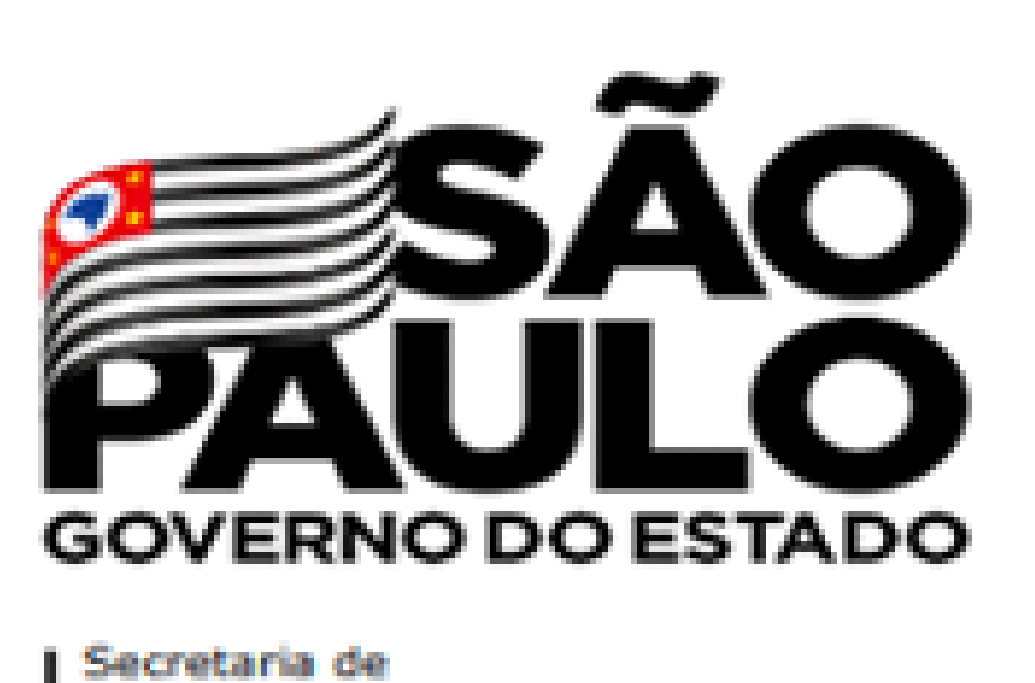
I Sacretaris de

Carolina de Jesus Couceiro de Freitas, Erica Fontana Miranda, Gabriela Nascimento de Azevedo Asaeda, Shirley Aparecida Lima e Wiviane Falasca Pereira

\title{
EQUIPE DE REMOÇÃO ESPECIALIZADA EM DEPENDÊNCIA QUÍMICA: UMA ESTRATÉGIA DE QUALIDADE NA ASSISTÊNCIA DE ENFERMAGEM EM UM CENTRO DE REFERÊNCIA
}

Avaliação e Qualidade do Cuidado

\section{INTRODUÇÃO}

O Centro de Referência de Álcool Tabaco e Outras Drogas - CRATOD, atua em parceria com a Associação Paulista para o Desenvolvimento da Medicina (SPDM), no centro de São Paulo, prestando assistência à população na região conhecida como "cracolândia", disponibilizando o acesso á assistência médica, apoio social e quando necessário, a internação no serviço e/ou conveniados. Devido à demanda e a singularidade de cada paciente, a equipe de saúde do CRATOD é composta por profissionais especializados em dependência química e/ou transtornos mentais, com o intuito de garantir a melhor assistência prestada. As equipes de enfermagem prestam serviços 24 horas por dia. Os Enfermeiros realizam avaliação de risco inicial, em consonância com os preceitos do SUS, visando minimizar os riscos psíquicos e/ou clínicos. Os pacientes considerados em situação de "urgência" ou "emergência" pela avaliação de risco, são encaminhados para avaliação médica a partir da qual poderão ser encaminhados de modo "voluntário" ou "involuntário" para a unidade de observação do CRATOD, onde podem permanecer de 2472 horas. O setor observação possui uma equipe de enfermagem devidamente capacitada para as rotinas de um pronto atendimento e para o manejo de situações agudas. E esse cuidados prestado por profissionais especializados se estende ao momento de remoção desses pacientes para outros serviços, conforme demandas apresentadas ou conduta da equipe.

\section{OBJETIVO}

Descrever o trabalho realizado pela equipe da remoção e a importância de uma equipe especializada para realizar transferência do paciente dependente químico.

\section{MÉTODO}

Relato de experiência e análise descritiva dos dados referentes a equipe de remoção especializada.

\section{RESULTADO}

Após o período de avaliação médica e psicossocial, os pacientes que ainda necessitam de tratamento em enfermarias para desintoxicação hospitalar ou aqueles que durante o período de observação apresentaram complicações clínicas, são removidos com o auxílio de uma equipe de enfermagem especializada. Cada equipe é composta por enfermeiros e técnicos de enfermagem, sendo um deles o líder da equipe denominado Enfermeiro Referência, que tem a função fundamental na organização do processo de trabalho, no dimensionamento da equipe de remoção e registro de todas as informações pertinentes aos procedimentos necessários a logística de transferência dos pacientes com qualidade. 0 enfermeiro tem papel fundamental na equipe da remoção, sendo esse o profissional responsável por realizar a avaliação de risco do paciente a ser removido e sinalizando os principais riscos e discutindo com equipe multiprofissional as intervenções propostas afim de reduzir os mesmos. Desde abril/2014 até abril/2018 foram realizadas aproximadamente 17.000 mil remoções, em média, 337 pacientes por mês.
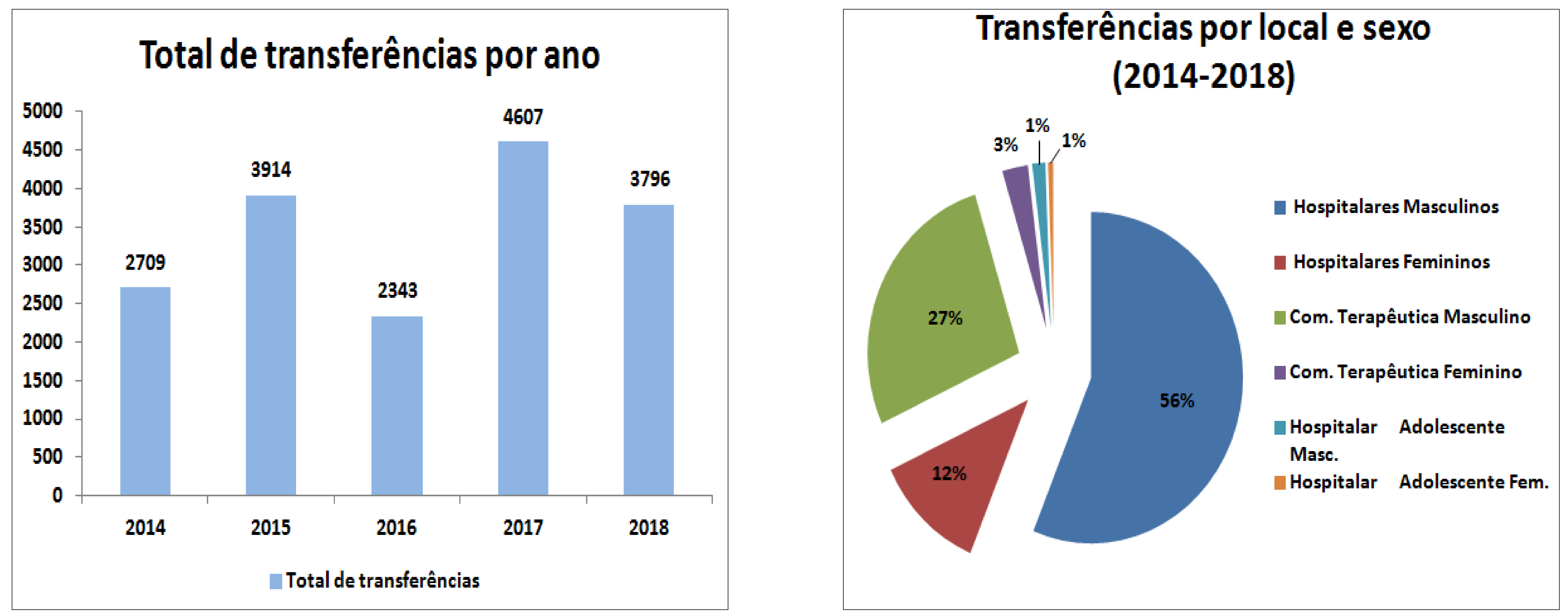

\section{CONCLUSÃO}

A Classificação de Risco proporciona um cuidado pautado na qualidade da assistência prestada ao paciente que busca o serviço de pronto atendimento em dependência química, possibilitando um cuidado seguro e humanizado. 